Research Article

\title{
Experimental Research on Simulation Material for Water-Resisting Soil Layer in Mining Physical Simulation
}

\author{
Tao Yang $\mathbb{D}^{1,2}$ and Jie Zhang $\mathbb{D}^{1,2}$ \\ ${ }^{1} X i$ 'an University of Science and Technology, Xi'an 710054, Shaanxi, China \\ ${ }^{2}$ Key Laboratory of Western Mine Exploitation and Hazard Prevention with Ministry of Education, \\ Xi'an University of Science and Technology, Xi'an 710054, China \\ Correspondence should be addressed to Tao Yang; yangtao@xust.edu.cn
}

Received 17 October 2019; Accepted 28 December 2019; Published 16 January 2020

Academic Editor: Aniello Riccio

Copyright (c) 2020 Tao Yang and Jie Zhang. This is an open access article distributed under the Creative Commons Attribution License, which permits unrestricted use, distribution, and reproduction in any medium, provided the original work is properly cited.

\begin{abstract}
This paper focuses on the failure mechanism of a water-resisting soil layer with both coal excavation and seepage effect. Being taken the simulation principle of fluid-solid coupling as the research basis, we have established a new kind of experimental material for fluid-solid physical simulation (FPS). The material adopts river sand and clay as the aggregates, besides engine oil and low-temperature grease that are used as the gelatinizing agents. According to the relevant property testing on the experimental material, the mechanical parameters and seepage parameters of the material totally match the parameters of the soil layer, which satisfy requirements of the fluid-solid coupling experiment. Simultaneously, we have solved abundant material property problems, such as the material disintegration with water and visuality of water seepage in the simulation. Next, we have built up the FPS model to simulate coal excavation under water-bearing strata with the specific material. The results indicated that in the FPS, movement and failure mechanism of the water-resisting soil layer agree with the in-situ monitoring results. In addition, the revolution law of a mining-induced crack is also fitting the actual data. The mechanism of submarine seepage and its parameters on the material and the prototype are similar. All research results would be necessary for controlling mining-induced destroying of clay water-resisting property. Meanwhile, the model demonstrates that selection of the material and coupling parameters is valid. Finally, we can alter the material matching to obtain the layer materials with various characteristics, which would be applied in extensive experiments for studying soil layer failure and seepage simulation.
\end{abstract}

\section{Introduction}

Physical simulation as an experimental methodology combining simulation theory and dimensional analysis was put to solve mining problems by Kuznetsov (former Soviet Union) innovatively. In China, a lot of scholars made enormous contributions to the experimental methodology including "Experimental Rock Mechanics" by Pro. Y. M. Lin and "Physical simulation Experiment on Mining Ground Pressure" by Lin [1]. As we know that fluid-solid coupling is an interaction between fluid (water) and solid (rock and soil) in geotechnical engineering. The coupling effect contains deformation and failure of the rock and soil and flow characteristics from the fluid. Therefore, we mainly study the evolution mechanism of mechanical behavior and seepage trait after rock and soil failure with fluid flowing [2, 3]. Many fields of engineering technology would relate the fluid-solid problems such as mining engineering, petroleum engineering, hydraulic and hydro-power engineering, and so on. An accurate mechanism on fluid-solid coupling can control failure of water-resisting soil layer by mining excavation [4]. We studied the mechanism on fluid-solid coupling by theoretical analysis and numerical simulation. Now, fluidsolid physical simulation is a new way. In the way, we can determine experimental settings such as single factor or multifactor. Particularly, in the fluid-solid physical simulation with multifactors, we need a design fluid feature in the research course but not general simulation by only solid material. In the past, subjecting to proper two-phase simulation material, we seldom achieve fluid-solid two-phase 
simulation. However, the specific experimental material would be necessary for the fluid-solid coupling simulation. A few scholars including Jacoby and Schmeling [5], Wiens et al. [6], and Kincai and Olson [7] and the Yangtze River Water Resources and Hydropower Research Institute have attempted fluid-solid simulation with paraffin. However, previous simulation material was made up by single-solid medium, and few scholars emphasized on simulation theory and simulation material on fluid-solid coupling. Besides, in the involved experiment, the researchers simplified the twophase coupling with flexible loading akin to the water pressure. Obviously, there is a huge difference between the past simulation results and the actual monitoring situation. Red clay is a special and key aquiclude, which cannot be generalized as an ordinary rock stratum. In some mining areas, surface runoff and shallow sand phreatic water are the main water resources in the area. The red layer in the lower part of the area is responsible for the important task of blocking the water body from the coal seam working face. Therefore, the stability and integrity of the red layer will ultimately determine the water inrush during the coal seam mining process.

\section{Simulation Principle of Fluid-Solid Coupling}

After the Miocene, the terrain of central and Western China tends to be flat, and the climate is humid and hot. In Shaanxi, Shanxi, Henan, Gansu, and other places, in the Pliocene, river lake facies and red clay facies are widely accumulated. Especially in the Shanxi and Shaanxi area, brown red and bright red clays are widely accumulated, including tridactylus and rhinoceros. The laterite layer is mainly distributed in the central and western regions of China. $41^{\circ} \sim 42^{\circ}$ $\mathrm{n}$ is the northern boundary of laterite, $35^{\circ} \mathrm{n}$ up and down is the southern boundary of laterite, and Taihang Mountain and Longdong Longxi are the eastern and western boundaries, respectively.

The simulation principle of fluid-solid coupling needs determine simulation coefficients of elastics mechanics and hydromechanics of fluid-solid media desperately in the same settings with a fluid-solid coupling theoretical model for a continuous medium $[8,9]$. When we determine the simulation coefficients, simulation constants in the hydromechanics should be replaced with simulation constants in the elastics mechanics, which can achieve fluid-solid coupling simulation.

$$
\left\{\begin{array}{l}
{[T]\{H\}+[S]\left\{\frac{\partial H}{\partial T}\right\}+\{I\}=0,} \\
\{R\}[B]\{\Delta \delta\}_{e}=\frac{n \gamma}{E_{w}} \Delta H, \\
\left\{F_{w}\right\}+\left\{\Delta F_{w}\right\}=[K] \cdot\left[\{\delta\}+\{\Delta \delta\}_{e}\right] .
\end{array}\right.
$$

Here, $[T],[S]$, and $\{M\}$ are transmission matrix, storage matrix, and converge column matrix, respectively. $\{R\},[B]$, and $\{\delta\}_{e}$ are unit vector, unit stain vector, and unit displacement vector. $n, \gamma$, and $H$ are crack rate of rock-masses, water unit weight, and underwater head. $\left\{F_{w}\right\}$ and $\left\{\Delta F_{w}\right\}$ are equivalent nodal force by body force from water seepage. and relevant equivalent node force increment. Finally, $[K]$ is global stiffness matrix for the simulation model.

(1) According to simulation theory in elastics mechanics, $C_{G}=C_{E}=C_{\lambda}$. Besides, geometry, stress, and inertia force simulation settings are $C_{u}=C_{l}$, $C_{G}=C_{E}=C_{\lambda} C_{l}$, and $C_{t}=\sqrt{C_{l}}$ apart.

(2) According to simulation theory in hydromechanics, converge column, seepage coefficient, and storage rate simulation settings are, respectively, $C_{I}=$ $1 / C_{t}=1 / \sqrt{C_{l}}, \quad C_{K X}=C_{K Y}=C_{K Z}=\sqrt{C_{l} / C_{\gamma}} \quad$ and $C_{S}=C_{t} C_{I} / C_{H}=1 / C_{l} C_{\gamma}$.

\section{The Engineering Properties of Red Clay}

The main ingredients of red clay aquiclude are red-brown clay and loam, mineral composition is mainly chlorite based, it has $11 \%$ sand, $51 \%$ silt, and $38 \%$ clay, and void ratio is $0.6 \sim 0.89$, it is silty clay, compact in structure, and is in hard plastic state, and it has high strength and low compressibility. The results of physical and mechanical parameters of soil samples are shown in Table 1.

In order to test the seepage deformation characteristics of soil under seepage flow, through the water head pressure applied, the hydraulic pressure on the soil was measured. Main completed the clay try, grain size analysis, fluid density and water content, plastic limit, and penetration test. Step by step under the set seepage water pressure on the upper load to stable. In the seepage water pressure for $10 \mathrm{kPa}, 20 \mathrm{kPa}$, $30 \mathrm{kPa}$, and $40 \mathrm{kPa}$ cases of head seepage deformation test showed that the basic seepage deformation was positively correlated, stronger water-resisting layer. The experimental results are shown in Table 2.

\section{Simulation Material Selection}

4.1. Principle on Material Selection. In the physical simulation experiment, proper material selection would be crucial for the experiment $[10,11]$. With relevant simulation theory, simulation material should satisfy the simulation principle for fluid-solid coupling and other basic properties. Specially, the simulation material for the fluid-solid coupling needs be nonhydrophilic, low permeability, and plastics deformation. Moreover, nonhydrophilic material is similar with the prototype in the mechanical characteristic aspect. We have finished related simulation material on rock-water twophase experiment and confirmed low-fusibility high-quality paraffin $\left(42^{\circ} \mathrm{C}-54^{\circ} \mathrm{C}\right)$ as the gelatinizing agents [12]. Simultaneously, simulation material should meet sealing, which do not influence the movement mechanism of the rock and soil layer. In the end, we need to simulate failure mechanism of the rock and soil layer and crack evolution characteristics. The crack would emerge by the mining excavation rather than the artificial water seepage channel, and water seepage through the crack should be visual. 
TABle 1: Physical and mechanical properties of red clay.

\begin{tabular}{|c|c|c|c|c|c|c|c|c|}
\hline \multirow[b]{2}{*}{$\begin{array}{l}\text { Red } \\
\text { clay }\end{array}$} & \multicolumn{4}{|c|}{ Physical properties } & \multicolumn{4}{|c|}{ Mechanical properties } \\
\hline & $\begin{array}{c}\text { Water } \\
\text { content } W \\
(\%)\end{array}$ & $\begin{array}{l}\text { Void } \\
\text { ratio } e\end{array}$ & $\begin{array}{c}\text { Porosity } \\
n / \%\end{array}$ & $\begin{array}{l}\text { Cohesive } \\
\text { force } c \\
(\mathrm{kPa})\end{array}$ & $\begin{array}{c}\text { Internal } \\
\text { friction angle } \varphi \\
\left(^{\circ}\right)\end{array}$ & $\begin{array}{l}\text { Coefficient of } \\
\text { compressibility } \\
\mathrm{MPa}^{-1}\end{array}$ & $\begin{array}{c}\text { Modulus of } \\
\text { compression Es } \\
\text { (Mpa) }\end{array}$ & $\begin{array}{c}\text { Unconfined } \\
\text { compressive strength } q_{n} \\
(\mathrm{kPa})\end{array}$ \\
\hline & $11.3 \sim 17$ & $0.6 \sim 0.89$ & $38 \sim 46.1$ & $42 \sim 98$ & $27.8 \sim 33$ & $0.1 \sim 0.25$ & $8 \sim 21$ & $110 \sim 151$ \\
\hline
\end{tabular}

TABle 2: The water-physical property of red clay.

\begin{tabular}{|c|c|c|c|c|c|c|}
\hline Lithology & Liquid limit $\left(W_{1}\right) \%$ & Plastic limit $\left(W_{\mathrm{p}}\right) \%$ & $\begin{array}{l}\text { Permeability coefficient } \\
(K) \mathrm{mm} / \mathrm{h}\end{array}$ & Saturability $\left(S_{r}\right) \%$ & $\begin{array}{c}\text { Coefficient of } \\
\text { collapsibility }\left(\delta_{s}\right)\end{array}$ & $\begin{array}{l}\text { Flee swelling } \\
\text { ratio }\left(\delta_{c t}\right) \%\end{array}$ \\
\hline Red clay & $25.1 \sim 31.5$ & $16.6 \sim 18.3$ & $10.24 \sim 26.25$ & $40.2 \sim 65.5$ & $0 \sim 0.005$ & $1 \sim 18$ \\
\hline
\end{tabular}

4.2. Aggregate and Gelatinizing Agent Selection. In general, we made specimens with various matching on the aggregate and gelatinizing agents and obtained related mechanical and seepage parameters [13]. We determine the aggregate by the prototype composition, property, and experimental purpose. According to former research results, river sand and clay can get low-strength simulation material. River sand mainly offers strength and brittleness. With the same relative density, the internal friction angle of the river sand is larger due to larger superficial roughness of the sand particle. When the sand particle is oversize, permeability of the simulation material would increase remarkably. On the contrary, fine sand which has the larger surface area, would integrate with the gelatinizing agent better. Material made by various particle size sand would reduce the void rate and when $C_{u}>5$, the seepage rate of the material would decrease obviously. Therefore, the material should choose the river sand with good psephicity and small particle size.

Clay mainly represents plastic traits. According to the geological investigation in coal mine restrict, the north part of Shaanxi Province, China, stone loess is comprised by loam and sub-sand. Hipparion red soil is consist of clay, sandy clay with compact structure. Considering high content of mineral in the water-resisting clay, the crack be induced by the coal excavation would be close promptly, so we should choose the clay with low permeability and solid deformation behavior.

Engine oil and low-temperature grease were chosen as the gelatinizing agents. Engine oil, which is the machine oil addicting thickening agent and lubricant additive presenting semi-solid state mechanical parts lubricant, was applied for controlling nonhydrophilia of the material. Besides, lowtemperature grease called mineral grease, which was white or faint yellow cream, provided large plastic deformation. The grease had good stickiness, lipophilicity, high density, and good waterproofness.

4.3. Preliminary Trial for Simulation Material. The strength and water-physical property test of the material would be crucial in the simulation material experiment. We adopted the technical geotechnical facilities to make the material specimens, particularly the gelatinizing agents, which have obvious influence on the material strength. We employed high-precision physical balance to weigh up related indigents. Based on the experimental matching, the aggregates and gelatinizing agents would be blended evenly with automatic agitator kettle. Simultaneously, we heated and stirred the mixture for two reasons: (1) the aggregates can mix with the gelatinizing agents after fusion; (2) the mixture would be heated evenly. In order to ensure the specimen quality and take apart the specimen, we would smear lubricant on the internal surface of the specimen mould before manufacturing the specimens, which can guarantee the specimen quality. The heated experimental materials were easy to bond the mould, so we used the bipartition mould to make cylinder specimens. The mixture would pour into the mould, and we tamped it tightly. When the experimental materials have been cooled, we took apart the relative mould. The specimens needed to be conserved due to low strength after taking apart the moulds. Each group with various matching has triple specimens being numbered for subsequent testing. The specimens for experimental materials are shown in Figure 1(a). We set the ratio of sand with soil $1: 1$ as the initial value and obtained the mechanics and waterphysical properties being influenced by the engine oil and low-temperature grease. Next, we altered the matching of the aggregates to obtain relevant impact on the properties. Figures 1(b)-1(f) indicated the relevant experiments. The results showed that the specimen would disintegrate after 48 hour soaking. The experimental material was nonhydrophilic obviously. When the specimens were compressed, dilatation was clear in the centre of specimens, which was similar with failure behavior of the waterresisting layer. Moreover, liquid limit moisture content of the material is $34.01 \%$ and plastic limit moisture content is $25.21 \%$. The plasticity index $\left({ }_{\mathrm{PI}}\right)$ is 8.8 and liquidity index is ranged from 0.25 to 0.75 with good plasticity.

\section{Material Experiment Analysis}

Based on former abundant testing results, we have known the mechanics and water-physical properties of the materials basically. We schemed the various matching of sand and soil including $2: 1,1: 1,1: 2,1: 3$, and $1: 5$. Simultaneously, the gelatinizing agent ratio adopted $4: 1,6: 1,8: 1$, and $10: 1$. The relative results are shown below. 


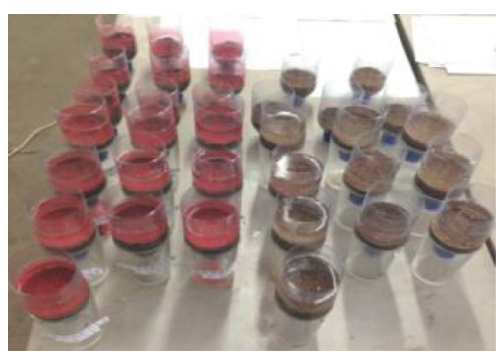

(a)

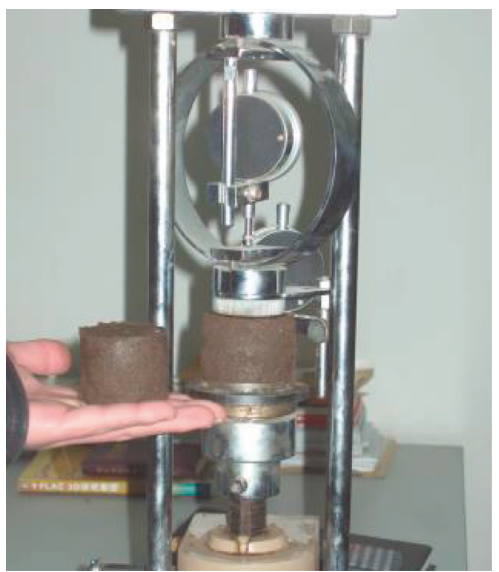

(d)

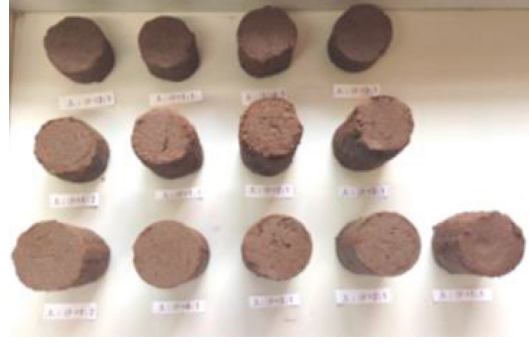

(b)

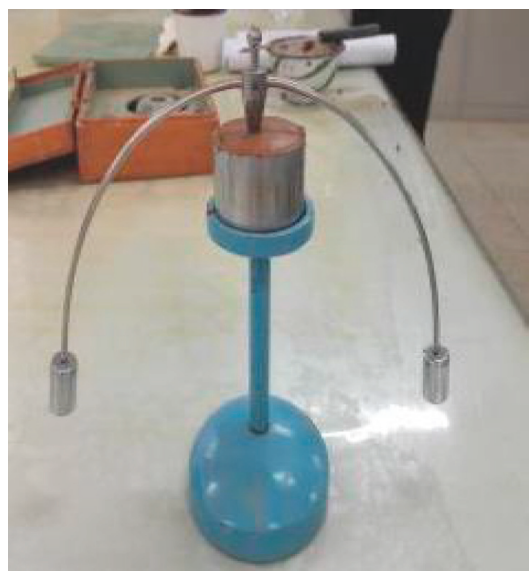

(e)

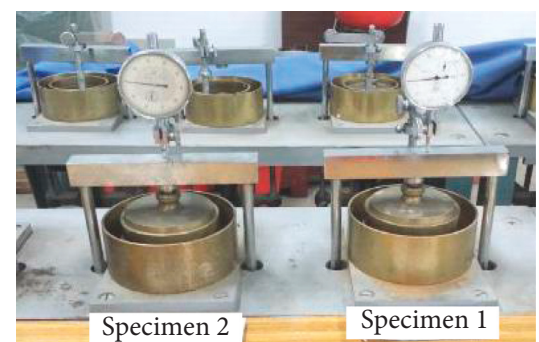

(c)

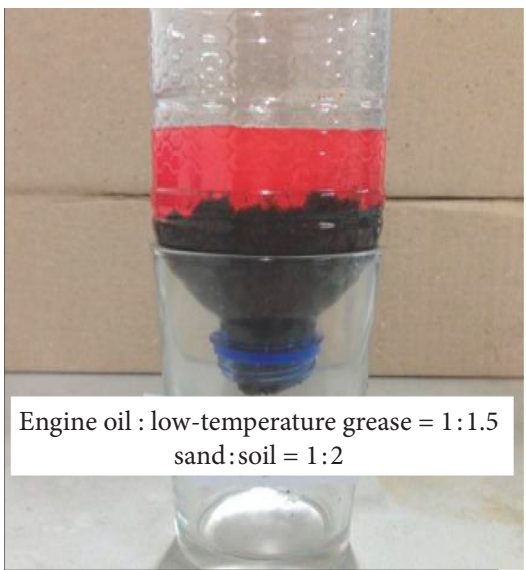

(f)

FIGURE 1: Simulation material testing process. (a) Specimen for simulation material. (b) Water-resisting performance testing. (c) Material concretion testing. (d) Compressive strength testing. (e) Liquid and plastic limit testing. (f) Permeability coefficient testing.

\subsection{Material Strength Influence by the Ratio between Sand and} Soil. When the gelatinizing agent ratio was constant, sand as the aggregate had a large impact on the material mechanic characteristics. Values of material strength and elastic modulus would increase to a specific value and then decrease remarkably with the decreasing ratio. When the ratio was 2 : 1 , the specimen strength was lower due to inadequate cement of the aggregates. When the ratio was $3: 1$, the curve tendency after peak value was similar. When the gelatinizing agent ratio increased from $6: 1$ to $10: 1$, the gelatinizing agent had a huge effect on deformation behavior of the materials. Figure 2 shows the stress-strain curve with various ratios between sand and soil, when the gelatinizing agent ratios were $6: 1$ and $10: 1$, respectively.

\subsection{Material Strength Influence by Engine Oil and Low-} Temperature Grease. Here, the influence was mainly performed on the plasticity of the material by engine oil, and low-temperature grease has a large effect on the permeability behavior of the material. When we just used a single kind of the gelatinizing agent, material strength always decreased with the decreasing ratio between the aggregate and the gelatinizing agent. However, we adopted both gelatinizing agents for the simulation materials, which was better for the permeability experiment. Figure 3 indicates the stress-strain value on the grease ratio with the ratio between sand and soil, $1: 3$ and $1: 5$.
5.3. Material Strength Influence by Ratio Between the Aggregate and the Gelatinizing Agent. In each specimen, the ratio between engine oil and low-temperature grease was 1 : 1 generally. With the same ratio between sand and soil, the strength of material would decrease obviously with the ratio between the aggregate and the gelatinizing agent. Specially, the ratio between sand and soil was down to $1: 3$, and the curve kept steady remarkably. When the ratio continued to decrease, the postpeak value decreased quickly with distinct plasticity. Figure 4 shows the stress-strain curve with the ratio between sand and soil, $1: 1$ and $1: 3$.

5.4. Proper Analysis on Material Matching. In general, the strength of the material would decrease with the increment of the ratio between sand and soil and between the aggregate and the gelatinizing agent. Stress-strain curves with various matching were totally similar with the curve from the prototype, which can satisfy the experiment settings well. With multi-target orthogonal experiment, the experiment should meet two index requirements. Firstly, the proportion between engine oil and low-temperature grease should be equal because the grease ratio has a few impacts on the mechanical property of materials. From the above analysis, the specimens with the ratio between sand and soil $1: 5$, whose mechanical properties were similar with the property of soil furthest. Therefore, we finally decided the reasonable matching, which is the ratio between sand and soil $1: 5$ and 


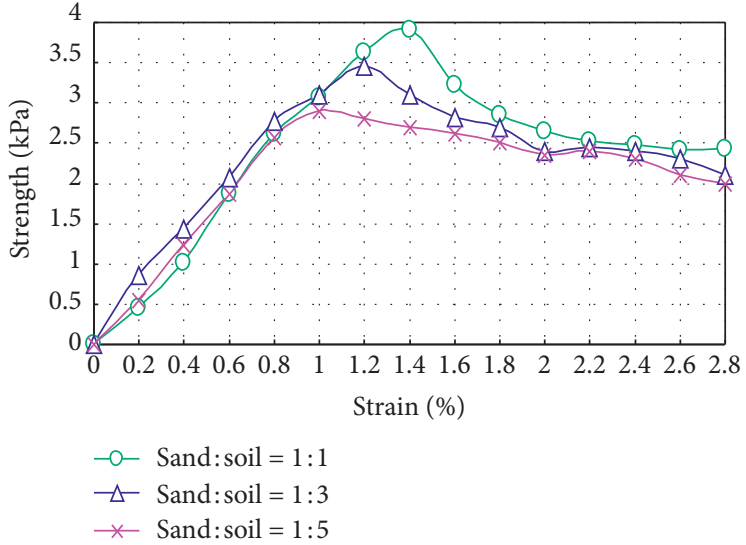

(a)

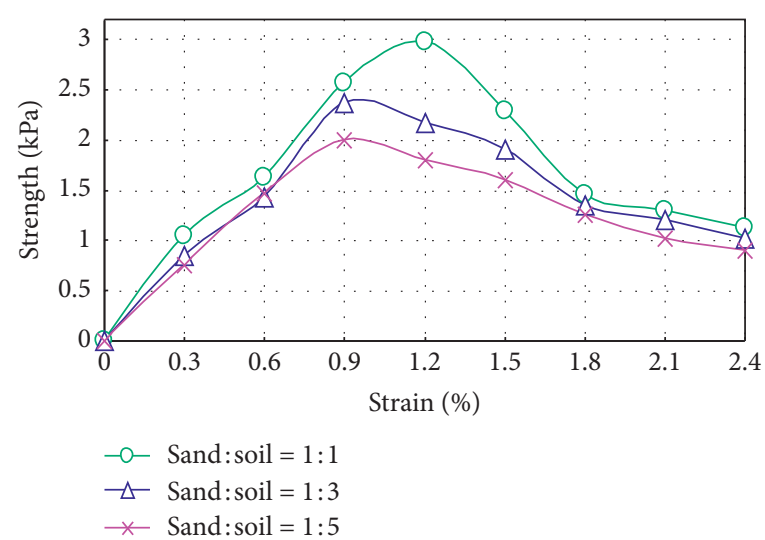

(b)

FIGURE 2: Stress-strain curve in various ratios between sand and soil. (a) Gelatinizing agent ratio $10: 1$. (b) gelatinizing agent ratio $6: 1$.

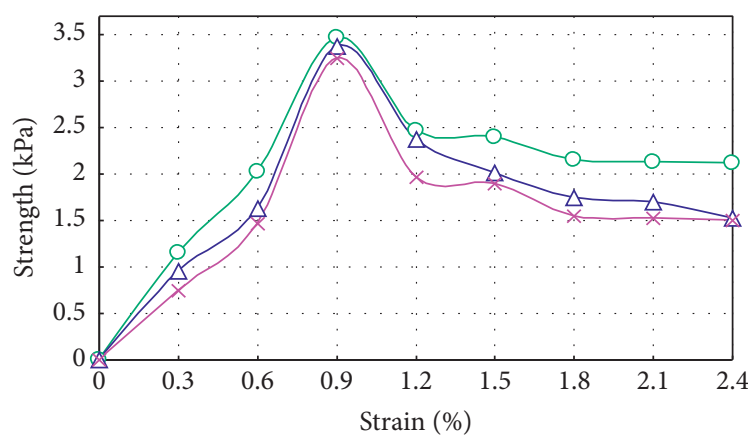

Engine oil:low-temperature grease

$-\circ-3: 1$

$\neg-1: 1$

$\leftarrow 1: 3$

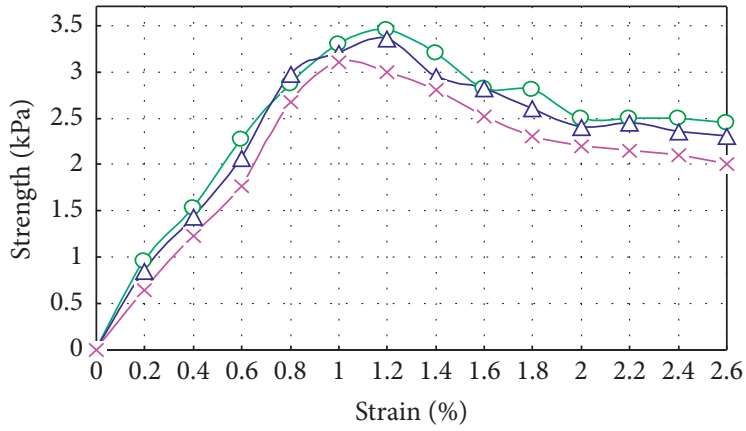

Engine oil:low-temperature grease

$-0-4: 1$

$\triangle-1: 1$

$\leftarrow 1: 4$

(a)

(b)

Figure 3: Stress-strain curve in various grease ratios. (a) Ratio between sand and soil $1: 3$. (b) Ratio between sand and soil $1: 5$.

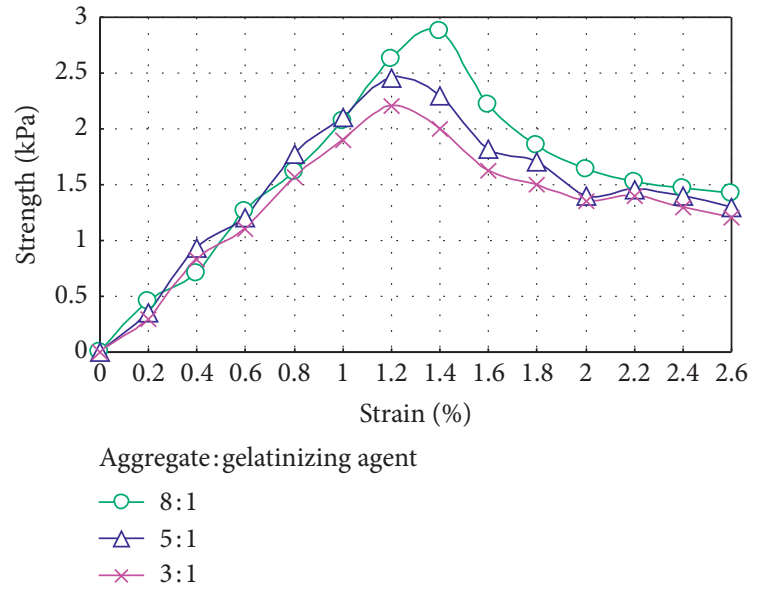

(a)

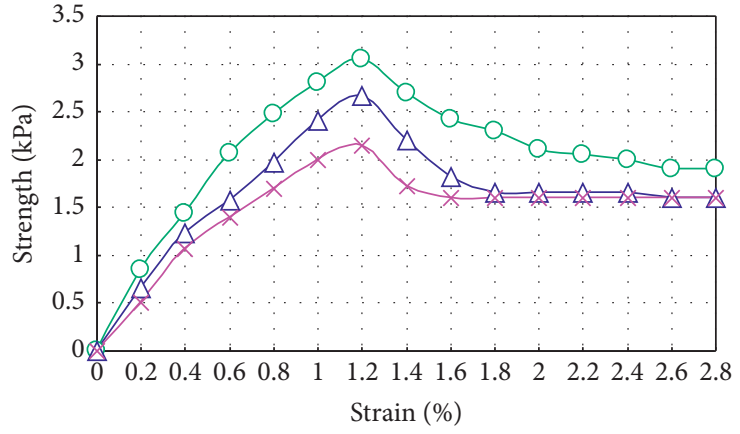

Aggregate: gelatinizing agent

- $-10: 1$

$\neg-6: 1$

$\leftarrow 4: 1$

FIgURE 4: Stress-strain curve in various ratios between the aggregate and the gelatinizing agent. (a) Ratio between sand and soil $1: 1$. (b) Ratio between sand and soil $1: 3$. 
Table 3: Permeability coefficient of each experimental material.

\begin{tabular}{cccccccccc}
\hline \multicolumn{2}{c}{ Ratio between aggregate and gelatinizing agent } & $4: 1$ & $5: 1$ & $6: 1$ & $7: 1$ & $8: 1$ & $9: 1$ & $10: 1$ & $11: 1$ \\
\hline & Specimen 1 & 1.25 & 1.48 & 1.69 & 2.31 & 2.85 & 3.63 & 3.91 & 4.32 \\
Permeability coefficient $\left(\mathrm{mm} \cdot \mathrm{h}^{-1}\right.$ ) & Specimen 2 & 1.21 & 1.41 & 1.61 & 2.29 & 2.86 & 3.50 & 3.89 & 4.28 \\
& Specimen 3 & 1.19 & 1.46 & 1.68 & 2.33 & 2.89 & 3.58 & 3.85 & 4.31 \\
& Average & 1.22 & 1.45 & 1.66 & 2.31 & 2.87 & 3.57 & 3.88 & 4.30 \\
\hline
\end{tabular}

the grease ratio $1: 1$. However, the ratio between the aggregate and the gelatinizing agent should be conformed further by the permeability testing.

\section{Material Permeability Testing}

The material permeability testing mainly ensured the ratio between the aggregate and the gelatinizing agent. According to Darcy's law, we adopted hydraulic conductivity methodology to measure the permeability coefficient of the material. The relative formula for the permeability coefficient is as follows:

$$
K=\frac{Q \times L}{t_{n} \times S \times(h+L)} .
$$

In which $K$ is permeability coefficient, $\mathrm{mm} / \mathrm{h}$. $L$ is thickness of experimental material, $\mathrm{mm}$. $h$ is thickness of the water layer, and mm. $t_{n}$ is time interval, hour. Here, $Q$ can be regarded as follows:

$$
Q=\frac{\left(Q_{1}+Q_{2}+Q_{3}+\cdots Q_{n}\right)}{N} .
$$

In which $Q$ is average amount of water, $\mathrm{mm}^{3} . Q_{1}, Q_{2}, \ldots$, and $Q_{n}$ are amount of water in each permeability, and $\mathrm{mm}^{3}$. $S$ is cross-section area, $\mathrm{mm}^{2}$. After 48 hours soaking, we started the testing and use water drum to gather the permeable water. The model needed 1 hour to achieve steady status, and then we used timer and read the data each hour $\left(Q_{1}, Q_{2}, \ldots\right.$, and $\left.Q_{n}\right)$. Table 1 lists the permeability coefficient in eight groups with various gelatinizing agent amounts, which are from large to small. We can conclude that the smaller the proportion of the gelatinizing agent, the larger the permeability coefficient, which indicates that more loose the material, the larger the permeability coefficient. Combining indigent and structure analysis on the soil group, we can conclude that the more compact structure of the soil group, the more weak permeability coefficient.

The permeability coefficient value of field soil is $10.24-26.25 \mathrm{~mm} / \mathrm{h}$ by the testing [14]. The geometric simulation constant is 100 and the weight simulation constant is 1.56 in the experiment. Considering the fluid-solid coupling simulation principle, the permeability coefficient simulation constant is 6.4. Therefore, we can calculate the permeability coefficient of the simulation material is $1.62-4.10 \mathrm{~mm} / \mathrm{h}$. Analyzing the data in Table 3, the experimental material satisfies requirements of the simulation experiment and is similar with the soil.

\section{Simulation Model Analysis}

7.1. Investigation on Geological Settings and Model Schemes. Destruction of geological environment by coal excavation is more and more serious in Shenfu coal district. Particularly, we focus on the destruction of water resources [15]. When the height of excavated coal is about $2.0 \mathrm{~m}$ and the waterresisting layer is weak clay strata, the actual operation could achieve water protection mining, if the water-resisting layer would recover water-resisting performance after slight failure [16]. Therefore, we studied the evolution mechanism of water flowing cracks in the soil layer and analyzed the cracks effect on the water-resisting property. Next, protection measurement on water-resisting layer has been proposed finally after mastering the relation between soil layer failure and overlying water body. The measurement can promote substantial and rational development of regional economics and has important theoretical significance and application value [17]. We set No. $2^{-2}$ working face as the research area. Here, the average angle of the coal seam is 1.5 degrees and excavated height is $2.0 \mathrm{~m}$. Overlying strata are loose layers and $15 \mathrm{~m}$ hipparion red soil in the Tertiary. The soil in the research area has tight structure and is medium hard. The void ratio of the soil is $0.70-0.83$ and relevant permeability coefficient is $0.0058-0.6300 \mathrm{~m} / \mathrm{d}$. Besides, the phreatic layer lies above the loose layer [18-21]. The main mechanical parameter for overburden strata is shown in Table 4.

We have established the fluid-solid coupling physical simulation model with a geometry scale of $1: 100$. The specific excavation method simulated actual longwall mining and the excavated height of coal seam was $2.0 \mathrm{~m}$. We set $30 \mathrm{~m}$ boundary coal pillars which lied both in left and right sides of the model. Figure 5 indicates the model situation before and after the model excavation.

7.2. Model Result Analysis. The experiment results indicated that coal roofs emerge a large-scale collapse when the working face advances $7 \mathrm{~m}$ and the collapse height reaches up to $15 \mathrm{~m}$ or so. With the working face advancing increasingly, the periodical collapse of the coal roof is presented and mining-induced cracks gradually develop upward until the working face advances $150 \mathrm{~m}$. Generally speaking, the final height of the caving zone is about $20 \mathrm{~m}$ and the height of the fissure zone can be up to $36 \mathrm{~m}$. In particular, few small cracks have been developed in the bottom of the water-resisting layer. Remarkable submergence has happened in the soil layer; however, cracks never connect the soil layer. In the whole experiment, the phreatic water level kept steady. Although the water-resisting soil layer has the function of water resisting, seepage will occur inside, and slight seepage will occur in the water body, which will lead to the decline of surface water.

Data statistics of typical measuring points $A, B, C, D, E$, and $F$ in the caving zone, fracture zone, and bending subsidence zone of overburden are shown in Table 5. The 
TABLE 4: Mechanical parameters of overlying strata above working face.

\begin{tabular}{|c|c|c|c|c|c|}
\hline $\begin{array}{l}\text { Serial } \\
\text { number }\end{array}$ & Lithology & $\begin{array}{c}\text { Thickness } \\
(\mathrm{m})\end{array}$ & $\begin{array}{c}\text { Density }\left(10^{3} \mathrm{~kg} /\right. \\
\left.\mathrm{m}^{3}\right)\end{array}$ & $\begin{array}{c}\text { Tensile strength } \\
(\mathrm{MPa})\end{array}$ & $\begin{array}{c}\text { Elastic modulus } \\
(\mathrm{GPa})\end{array}$ \\
\hline 8 & Loose phreatic aquifer & 20.0 & 1.6 & - & 2.0 \\
\hline 7 & Red soil layer & 15.0 & 2.3 & 1.84 & 6.0 \\
\hline 6 & Medium sandstone & 6.0 & 2.4 & 4.89 & 18.0 \\
\hline 5 & $\begin{array}{l}\text { Siltstone with medium and fine } \\
\text { sandstone }\end{array}$ & 10.0 & 2.3 & 4.84 & 13.0 \\
\hline 4 & Medium sandstone & 6.0 & 2.4 & 4.89 & 18.0 \\
\hline 3 & Siltstone & 4.0 & 2.5 & 3.90 & 8.0 \\
\hline 2 & Sandy mudstone & 4.0 & 2.5 & 3.62 & 7.0 \\
\hline 1 & Siltstone & 2.0 & 2.4 & 3.90 & 6.0 \\
\hline 0 & Coal seam & 2.0 & 1.3 & 0.70 & 1.5 \\
\hline
\end{tabular}

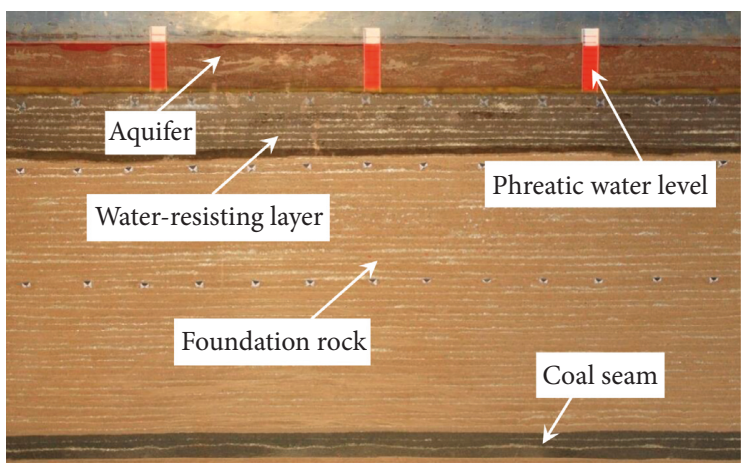

(a)

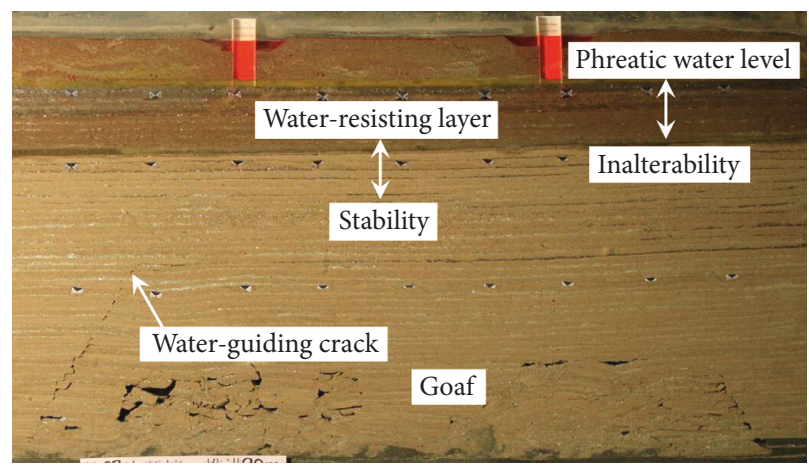

(b)

FIGURE 5: Simulation results. (a) The actual physical simulation model. (b) The model status after coal seam excavation.

TABLE 5: Settlement of measuring points.

\begin{tabular}{lcccccc}
\hline Points distance & $A$ & $B$ & $C$ & $D$ & $E$ & $F$ \\
\hline 15 & 0 & 0 & 0 & 0 & 0 & 0 \\
25 & -1.3 & -0 & 0 & 0 & 0 & 0 \\
35 & -1.7 & -1.7 & 0 & 0 & 0 & 0 \\
45 & -2.4 & -2.2 & -2 & 0 & 0 & 0 \\
65 & -2.6 & -2.5 & -2.4 & -2.1 & -0.9 & 0 \\
80 & -2.9 & -2.7 & -2.7 & -2.8 & -2.2 & 0 \\
95 & -2.9 & -2.7 & -3.2 & -3.1 & -2.4 & -2.9 \\
110 & -2.9 & -2.7 & -3.2 & -3.4 & -3.3 & -3.1 \\
123 & -2.9 & -2.7 & -3.2 & -3.4 & -3.6 & -3.5
\end{tabular}

excavation makes the subsidence of the rock stratum sudden, and the subsidence is the gradual expansion from the lower rock stratum to the upper rock stratum. When the mining face is divided into two layers, the settlement point of layer changes obviously, and the deformation is gradually stable as the mining continues. In the whole process of mining, the deformation of observation point of layer $A$ is smaller than that of layer $F$. It is proved that the destruction of overlying strata by mining has the characteristics of continuous transmission and layer by layer attenuation. When the mining bottom layer is pushed to $99 \mathrm{~m}$, the measuring point of the goaf corresponding to layer $f$ has a sudden collapse, and the collapse height is up to $3.4 \mathrm{~m}$.

From Figure 6, it can be seen that the subsidence deformation time of each typical point changes with the

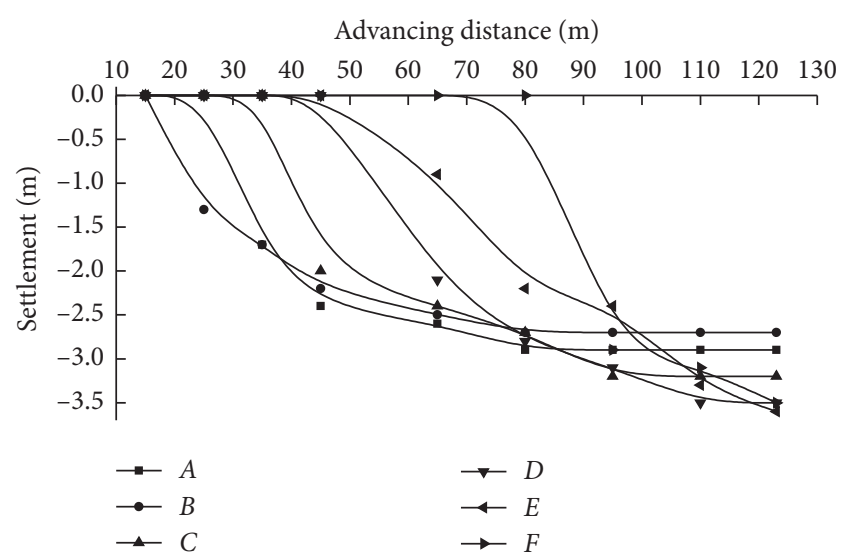

FIGURE 6: Subsidence curve of measuring point.

advance of the working face. Only when the working face is pushed under the measuring point, the measuring point begins to have obvious settlement changes. Other measuring points will not be greatly affected.

\section{Conclusion}

This paper developed a new physical material for fluid-solid coupling experiment based on fluid-solid coupling theories. We selected relevant materials for aggregates and gelatinizing agents. Moreover, the matching testing was also 
attempted and analyzed mechanical and water-physical properties. Finally, we adopted valid simulation materials and related matching. Main conclusions are following as:

(1) We deduced simulation settings for elastic mechanics of rock mass and hydromechanics of water with the fluid-solid coupling mathematical model. The theoretical basis for fluid-solid coupling is ensured with the related simulation principle.

(2) According to the mechanical property and material matching testing, we offer relevant experimental materials, which are nonhydrophilic with well and stable deformation performance. Considering coupling test data, the experimental materials can satisfy requirements for the fluid-solid coupling model.

(3) We have built up the simulation model setting $2^{-2}$ coal seam as the research area. The water-resisting layer is still steady with coal seam excavation. The water inrush and leakage seldom happened in the working face. The experimental results showed that movement and failure of overlying strata and crack evolution mechanism by the model coincided with the actual situation. Also, permeability laws and its parameters were also similar to in-situ monitoring results.

\section{Data Availability}

All data generated or analyzed during this study are included in this article.

\section{Conflicts of Interest}

The authors declare no conflicts of interest.

\section{Authors' Contributions}

T.Y. and J.Z. conceived and designed the experiments; T.Y. wrote the paper.

\section{Acknowledgments}

This study was supported by the National Natural Science Foundation of China (NO. 5147173, NO. 51774229); Shaanxi Innovation Capability Support Plan-Science and Technology Innovation Team Project (2018TD-038); and Shaanxi Natural Science Basic Research Plan (Shaanxi Coal Joint Fund) (2019JLM-41).

\section{References}

[1] Y. M. Lin, Experiment Rock Mechanics-Simulate Studying, China Coal Industry Publishing House, Beijing, China, 1984.

[2] S. F. Xue, X. H. Tong, and B. Q. Yue, "Progress of seepage rock mass coupling theory and its application," Journal of the University of Petroleum, vol. 24, pp. 109-115, 2000.

[3] S. Huang, Q. Liu, A. Cheng, Y. Liu, and G. Liu, "A fully coupled thermo-hydro-mechanical model including the determination of coupling parameters for freezing rock," International Journal of Rock Mechanics and Mining Sciences, vol. 103, pp. 205-214, 2018.
[4] J. Zhang, T. Yang, Y. L. Suo, D. Liu, and F. W. Zhou, "Roof waterinrush disaster forecast based on the model of aquiclude instability," Journal of China Coal Society, vol. 42, p. 2718 2724, 2017.

[5] W. R. Jacoby and H. Schmeling, "Convection experiments and the driving mechanism," Geologische Rundschau, vol. 70, no. 1, pp. 207-230, 1981.

[6] D. A. Wiens, S. Stein, C. Demets, R. G. Gordon, and C. Stein, "Plate tectonic models for Indian Ocean "intraplate" deformation," Tectonophysics, vol. 132, no. 1-3, pp. 37-48, 1986.

[7] C. Kincai and P. Olson, "An experimental study of subducting slab migration," Journal of Geophysical Research: Solid Earth, vol. 92, pp. 13831-13840, 1987.

[8] Z. G. Liu, The Relationship between Water Conducted Zone Height in the Moderate Hardness Cover Rocks and the Dimensions of the Strip Long-Wall, The Mining Science Research Institute, Beijing, China, 2004.

[9] F. Du and K. Wang, "Unstable failure of gas-bearing coal-rock combination bodies: insights into physical experiments and numerical simulations," Process Safety and Environmental Protection, vol. 129, pp. 264-279, 2019.

[10] J. Deng, L.-F. Ren, L. Ma, C.-K. Lei, G.-M. Wei, and W.-F. Wang, "Effect of oxygen concentration on low-temperature exothermic oxidation of pulverized coal," Thermochimica Acta, vol. 667, pp. 102-110, 2018.

[11] L.-F. Ren, Q.-W. Li, J. Deng, X. Yang, L. Ma, and W.-F. Wang, "Inhibiting effect of $\mathrm{CO}_{2}$ on the oxidative combustion thermodynamics of coal," RSC Advances, vol. 9, no. 70, pp. 41126-41134, 2019.

[12] J. Zhang and Z. J. Hou, "Experimental study on simulation materials of the solid-liquid coupling," Chinese Journal of Rock Mechanics and Engineering, vol. 23, pp. 3157-3161, 2004.

[13] J. Zhang, Z. J. Hou, and P. W. Shi, "Simulation materials experiment of the coupling seepage field and stress field in underground engineering," Journal of Liaoning Technical University(Natural Science), vol. 24, pp. 639-642, 2005.

[14] S. M. Wang, Q. X. Huang, L. M. Fan, Z. Y. Yang, and T. Shen, "Study on overburden aqclude and water protection mining regionazation in the ecological fragile mining area," Journal of China Coal Society, vol. 35, pp. 7-14, 2010.

[15] M. G. Qian, X. X. Miao, and J. L. Xu, Key Strata Theory in Ground Control, China University of Mining and Technology Publishing House, Xuzhou, China, 2000.

[16] C. Tang, "Numerical simulation of progressive rock failure and associated seismicity," International Journal of Rock Mechanics and Mining Sciences, vol. 34, no. 2, pp. 249-261, 1997.

[17] X. X. Miao, R. H. Chen, and H. B. Bai, "Fundamental concepts and mechanical analysis of water-resisting key strata in waterpreserved mining," Journal of China Coal Society, vol. 32, pp. 561-564, 2007.

[18] J. L. Xu, X. Z. Wang, W. T. Liu, and Z. G. Wang, "Effects of primary key stratum location on height of water flowing fracture zone," International Journal of Rock Mechanics and Mining Sciences, vol. 28, pp. 381-385, 2009.

[19] S. Q. Li, X. Q. He, S. Q. Li et al., "Experimental research on strata movement and fracture dynamic evolution of double pressure-relief mining in coal seams group," Journal of China Coal Society, vol. 38, pp. 2146-2152, 2013.

[20] M. G. Qian, "On sustainable coal mining in China," Journal of China Coal Society, vol. 35, pp. 529-534, 2015.

[21] E. Montes-Zarazua, A. Colin-Cruz, M. de la Luz Perez-Rea, M. de Icaza, C. Velasco-Santos, and A. Laura MartinezHernandez, "Effect of keratin structures from chicken feathers on expansive soil remediation," Advances in Materials Science and Engineering, vol. 2015, no. 10, Article ID 907567, 2015. 


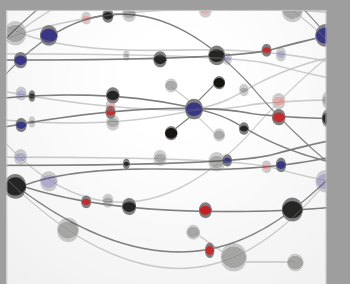

The Scientific World Journal
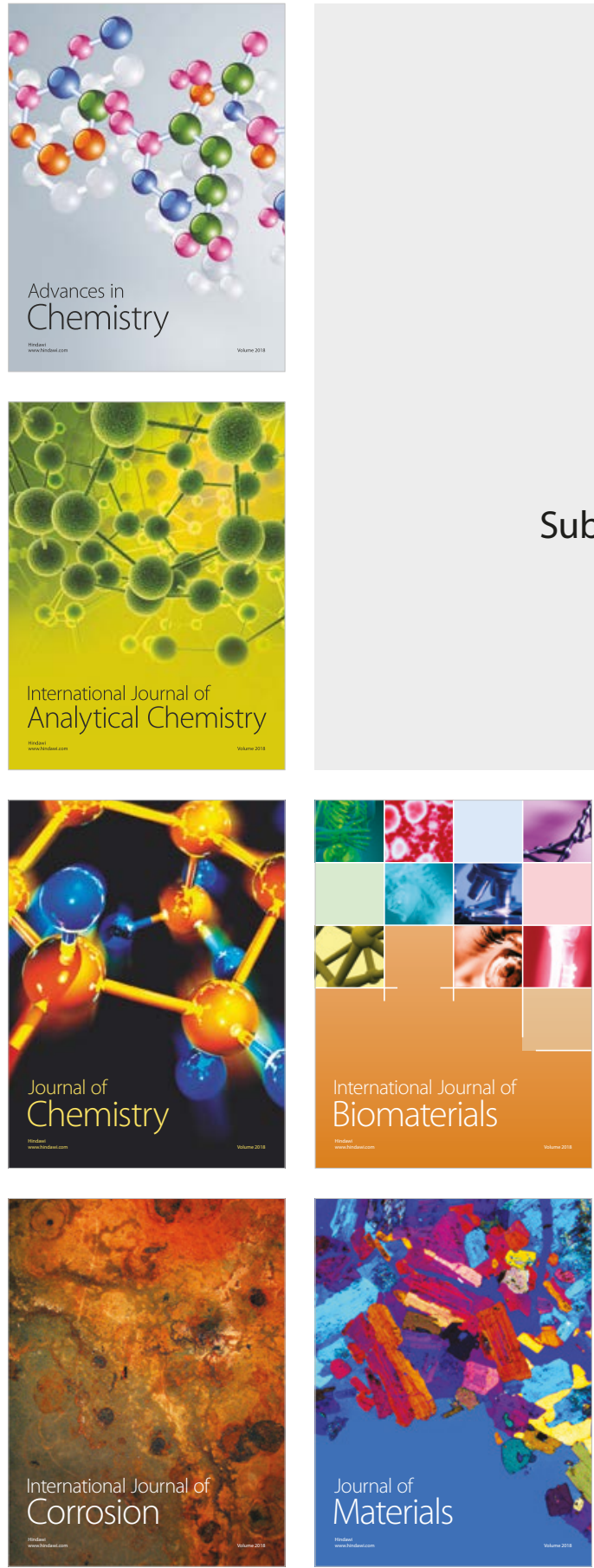

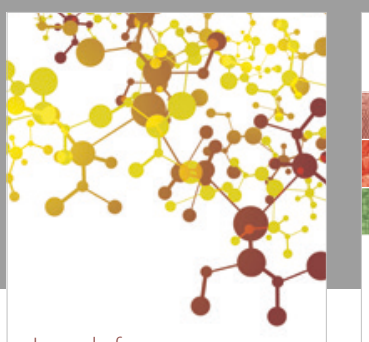

Journal of

Applied Chemistry
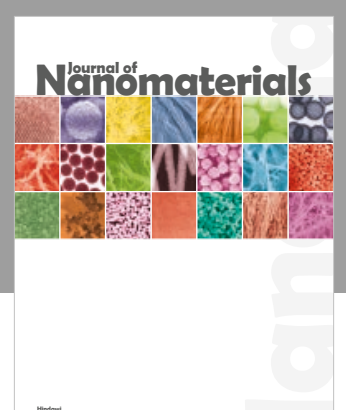

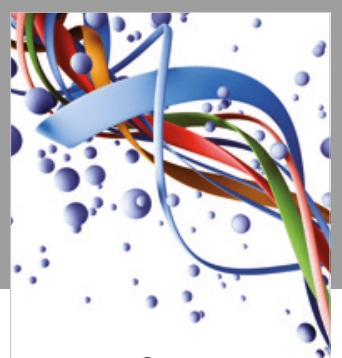

Scientifica

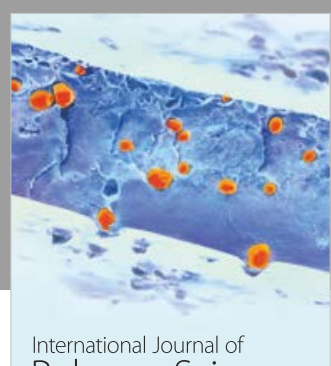

Polymer Science

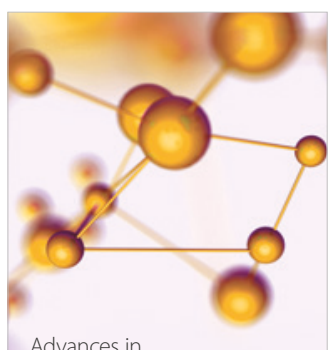

Physical Chemistry
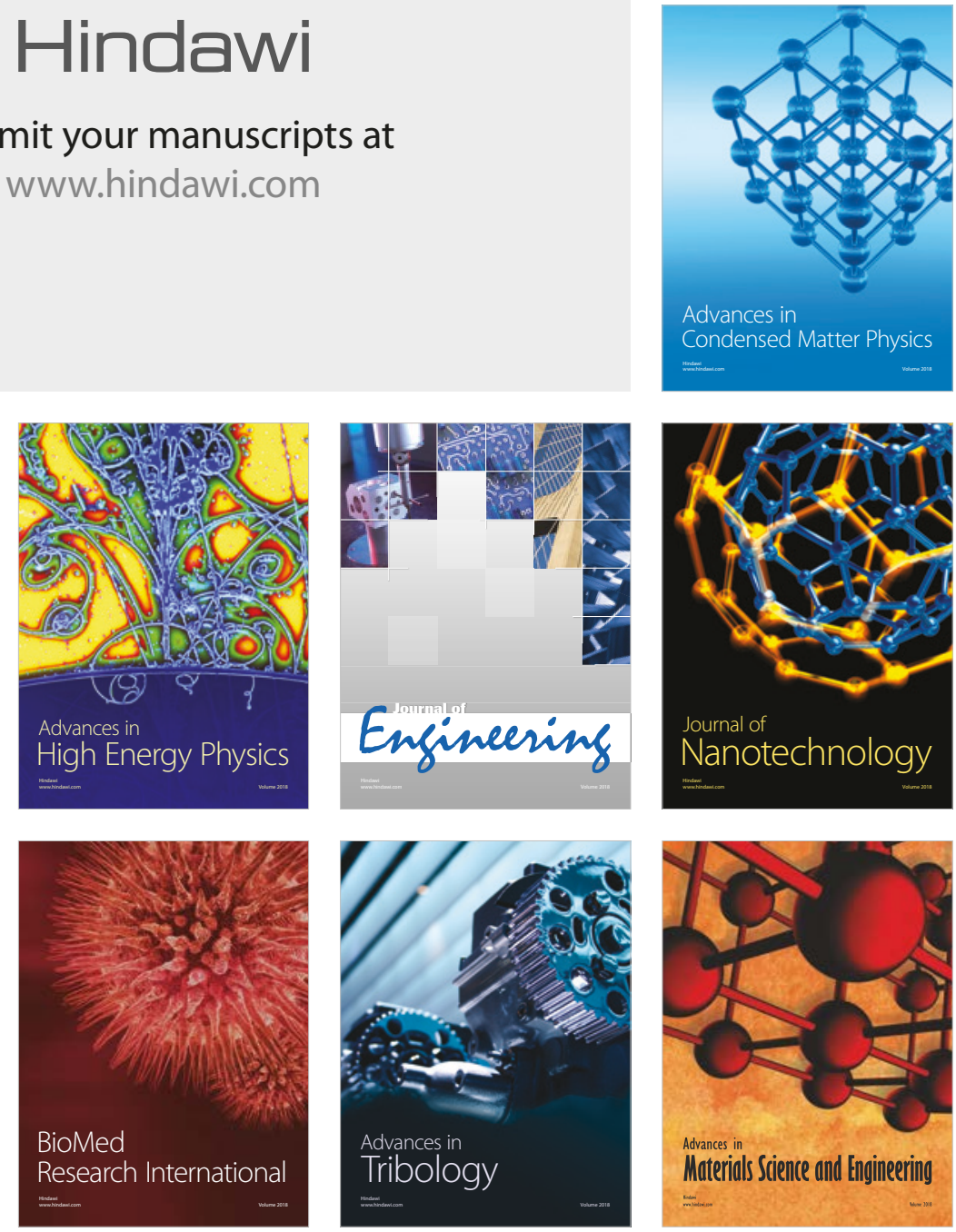